\title{
Transcriptomic characterisation and genomic glimps into the toxigenic dinoflagellate Azadinium spinosum, with emphasis on polykeitde synthase genes
}

Jan M Meyer ${ }^{1,2}$, Christian Rödelsperger ${ }^{2}$, Karsten Eichholz ${ }^{1,3}$, Urban Tillmann ${ }^{1}$, Allan Cembella ${ }^{1}$, Angela McGaughran ${ }^{2}$ and Uwe John ${ }^{*}$

\begin{abstract}
Background: Unicellular dinoflagellates are an important group of primary producers within the marine plankton community. Many of these species are capable of forming harmful algae blooms (HABs) and of producing potent phycotoxins, thereby causing deleterious impacts on their environment and posing a threat to human health. The recently discovered toxigenic dinoflagellate Azadinium spinosum is known to produce azaspiracid toxins. These toxins are most likely produced by polyketide synthases (PKS). Recently, PKS I-like transcripts have been identified in a number of dinoflagellate species. Despite the global distribution of $A$. spinosum, little is known about molecular features. In this study, we investigate the genomic and transcriptomic features of $A$. spinosum with a focus on polyketide synthesis and PKS evolution.
\end{abstract}

Results: We identify orphan and homologous genes by comparing the transcriptome data of A. spinosum with a diverse set of 18 other dinoflagellates, five further species out of the Rhizaria Alveolate Stramelopile (RAS)-group, and one representative from the Plantae. The number of orphan genes in the analysed dinoflagellate species averaged 27\%. In contrast, within the A. spinosum transcriptome, we discovered 12,661 orphan transcripts (18\%). The dinoflagellates toxins known as azaspiracids (AZAs) are structurally polyethers; we therefore analyse the transcriptome of $A$. spinosum with respect to polyketide synthases (PKSs), the primary biosynthetic enzymes in polyketide synthesis. We find all the genes thought to be potentially essential for polyketide toxin synthesis to be expressed in A. spinosum, whose PKS transcripts fall into the dinoflagellate sub-clade in PKS evolution.

Conclusions: Overall, we demonstrate that the number of orphan genes in the A. spinosum genome is relatively small compared to other dinoflagellate species. In addition, all PKS domains needed to produce the azaspiracid carbon backbone are present in A. spinosum. Our study underscores the extraordinary evolution of such gene clusters and, in particular, supports the proposed structural and functional paradigm for PKS Type I genes in dinoflagellates.

\section{Background}

Marine dinoflagellates are distributed worldwide from polar regions to tropical seas, where they typically constitute a considerable fraction of the plankton and thus affect the global carbon balance. Although dinoflagellates are often considered as phytoplankton because many are photosynthetic primary producers, other species are

\footnotetext{
* Correspondence: uwe.john@awi.de

${ }^{1}$ Ecological Chemistry, Alfred Wegener Institute for Polar and Marine

Research, Bremerhaven, Germany

Full list of author information is available at the end of the article
}

facultative or obligate heterotrophs. In addition, dinoflagellates are heavily represented among species known to form "harmful algae blooms" (HABs), thereby having strong impacts on ecosystem services and functioning and potentially affecting human health as their toxins are vectored through food webs into seafood [1].

Dinoflagellates comprise a well-supported monophyletic group based on both molecular data and many unique morphological characters [2]. The Dinophyceae belong to the Alveolata, together with the Ciliata and Apicomplexa. Compared to all other eukaryotes, the genome 
of dinoflagellates is highly unusual with respect to both structure and regulation [3-7]. The nucleus contains chromosomes that are permanently condensed throughout the cell cycle except during DNA replication [8,9], displaying a liquid crystalline state [10]. Dinoflagellate genomes are among the largest known among eukaryotes, ranging in size from 1.5 to $245 \mathrm{Gbp}$ [11]. The number of protein coding genes is relatively high and is proposed to range from 30,000 to 90,000 [12]. In addition to the structural peculiarities, the large genome size, high gene copy numbers, and a high content of repetitive genomic elements have made genome sequencing and assembly for dinoflagellate species a difficult task. Nevertheless, the draft assembly of the dinoflagellate, Symbiodinium minutum, which possesses one of the smallest reported dinoflagellate genomes (1.5 Gbp) was recently published [7]. Additional Transcriptomic studies (e.g. [13]) are beginning to focus research towards in-depth analysis of gene content in dinoflagellates.

The dinoflagellate Azadinium spinosum [14] is responsible for the production of potent toxins known as azaspiracids (AZAs) [15], which can accumulate in a variety of shellfish species, causing Azaspiracid Poisoning (AZP) - a severe gastrointestinal illness - in human consumers of such contaminated shellfish. Since the first report of AZP in 1995, AZAs have been found in shellfish from many western European countries and also from African, Chilean, and Chinese coastlines [16-20]. The presence of AZAs has been associated (in all confirmed cases) with members of the genus Azadinium, which now comprises more than a dozen species [21]. These observations indicate the widespread biogeographical distribution and potentially important ecological and socio-economic role of Azadinium.

The AZPs in Azadinium are polyether compounds with structural affinities to the polyketides, a complex and diverse class of secondary metabolites. The polyketides comprise not only potent toxins, but also many compounds with key biomedical functions, as antibiotics, insecticides, and immunosuppressive and anti-tumor agents [22]. Polyketides are synthesized by specific enzymes called polyketide synthases (PKS) through a series of condensation and reduction steps of acyl monomers. PKS enzymes are multi-functional complexes consisting of a minimal set of catalytic domains, namely ketoacylsynthase (KS), acyl transferase (AT) and acyl carrier protein (ACP), which are required for function. Three further domains (ketoacylreductases (KR), dehydrases (DH) and enolreductases (ER)) can be optionally present, and when present, these are responsible for the broad variety of polyketide structures found in dinoflagellates [23].

PKS enzymes can be classified into three groups according to structural and functional elements. Type I PKS enzymes are large multifunctional proteins, comprising either one big protein or organized into modules. In Type II PKS the different domains are organized as individual proteins, which form complexes for polyketide synthesis. The monofunctional, homodimeric Type III PKS act directly on acetyl-Coenzyme A during synthesis without requirement for ACP [24].

Type I PKS genes have been found in many prokaryotes and eukaryotes, including numerous fungi and bacteria [22], apicomplexa [25], haptophytes [26-28], chlorophytes [26] and dinoflagellates [5,29,30]. Phylogenetic analysis has revealed the existence of a protistian PKS clade consisting of apicomplexa, haptophytes, chlorophytes and dinoflagellates [30]. Yet these relationships do not reflect the proposed evolution of their source species [26,31] and therefore little is known about the origin and emergence of PKS genes. The widespread phylogenetic and biogeographical distribution of PKS genes among species provides an interesting tool to study evolution.

The genome size of $A$. spinosum has been estimated to be $9 \mathrm{Gbp}$ [32] and therefore falls into the smaller end of the size spectrum among dinoflagellates. With its widespread occurrence, toxic potential and relatively small genome size, A. spinosum is an interesting candidate for study in an evolutionary context. Here, we aim to achieve first insights into genome structure and organization of $A$. spinosum. We perform transcriptomic analysis, comparing data of A. spinosum with that of 18 other dinoflagellates (The Marine Microbial Eukaryotic Transcriptome Sequencing Project [33]), and three diatom species (the haptophyte Emiliania huxleyi, the cryptomonad Guillardia theta, and the chlorophyte Chlamydomonas reinhardtii) to identify orphan and homologous genes. Specifically, we analyse the transcriptome with respect to the enzymes involved in polyketide synthesis (Type I PKS) and thereby confirm that PKS from A. spinosum belong to the dinoflagellate Type I KS sub-group. We further show that the $A$. spinosum genome is less complex, based on sequence repeat structures within its noncoding regions, than that of other dinoflagellates with larger genome sizes, but does not deviate in a major way from the structure and organization typical of free-living dinoflagellates.

\section{Results}

\section{Features of the Azadinium spinosum genome}

The 454-shotgun sequencing on a GS Junior System yielded 103,860 high quality genomic reads (37 Mb) (GenBank accession number: SRR1576789). The dataset provided substantial insights into the genomic structure and organization of $A$. spinosum, although the total coverage was rather low for such a big genome. The distribution of genomic features in $A$. spinosum based upon sequence analysis with the program RepeatMasker [34] is given in Table 1 . This analysis revealed the overall genomic GC-content to be $49.7 \%$ which was lower than the 
Table 1 Genomic characteristics of Azadinium spinosum

\begin{tabular}{llll}
\hline Genomic feature & $\begin{array}{l}\text { No. of } \\
\text { elements }\end{array}$ & $\begin{array}{l}\text { Length } \\
\text { occupied (bp) }\end{array}$ & $\begin{array}{l}\text { (\%) sequence } \\
\text { analysed }\end{array}$ \\
\hline Small RNA & 163 & 30369 & 0.08 \\
Simple repeats & 27167 & 2357444 & 6.25 \\
Low complexity & 1949 & 164855 & 0.44 \\
Retrovirus & 69 & 64400 & 0.17 \\
Protein-coding & 860 & 374136 & 0.99 \\
No Database hit & - & 34748219 & 92.07 \\
Total & & 37739423 & 100 \\
\hline
\end{tabular}

*Small RNA comprises snRNA and scRNA.

transcriptome GC content of $60.3 \%$. About six percent of the assembled $A$. spinosum genome consisted of simple repeats 2-10 bp in length. Of these, repeats (ATG)n, (TTG)n and (CAT)n were the most common, accounting for $0.005 \%$ of the total number of bp. Low-complexity repeats, primarily poly-purine/poly-pyrimidine stretches, or regions of extremely high AT or GC content, made up $0.44 \%$ of the A. spinosum genome and, of these, A-rich repeats were most abundant followed by GA-rich and then G-rich repeats (Table 1).

Annotation of the genomic sequences with blastx against the Swissprot database using the blast2go tool resulted in a low annotation success of the genomic DNA data. From a total of 103,860 genomic DNA reads, 860 $(0.8 \%)$ were identified as potential coding sequence. This corresponds to $374,136 \mathrm{bp}$ ( $0.99 \%$ from a total of $37 \mathrm{Mb}$; Table 1), with an average read length of $472 \mathrm{bp}$. Combined with a retrovirus content of $0.17 \%$, the protein coding sequence in A. spinosum therefore accounts for $1.16 \%$ of the total genomic DNA (Table 1).

The ten most common genes found in the identified protein coding sequence are given in Table 2. Almost all of them belong to energy and primary metabolic pathways; exceptions are transcription factors and proteins involved in mRNA processing (Table 2).

\section{Features of the Azadinium spinosum transcriptome}

A total of 75,455 contigs were assembled after Illumina RNA sequencing, of which 844 were carrying the complete spliced leader sequence (DCCGUAGCCAUUUUGGCUCAAG, D = U, A or G). From these contigs, 69,956 protein fragments were predicted, of which 28,357 (40\%) could be assigned to proteins in the PFAM database with an $e$-value $<0.001$.

The completeness of the transcriptomic dataset was determined using the CEGMA tool, which represents a database of 458 highly conserved eukaryotic core genes present in a wide range of eukaryotic taxa [35]. In the A. spinosum transcriptome data, 430 (94\%) of these conserved gene families were detected. Additionally, we searched for the presence of key metabolic pathways enzymes (for
Table 2 Ten most common genes found in Azadinium spinosum genomic sequences

\begin{tabular}{|c|c|c|}
\hline Function & Reads & Blast2go annotation \\
\hline Energy metabolism & 41 & $\begin{array}{l}\text { uncharacterized mitochondrial } \\
\text { protein g00810 like }\end{array}$ \\
\hline Energy metabolism & 26 & cytochrome $c$ oxidase subunit $1^{*}$ \\
\hline Energy metabolism & 11 & cytochrome b complex III* \\
\hline Energy metabolism & 10 & $\begin{array}{l}\text { pentatricopeptide } \\
\text { repeat-containing protein* }\end{array}$ \\
\hline Photosynthesis & 56 & photosystem q protein* \\
\hline Photosynthesis & 29 & $\begin{array}{l}\text { photosystem i p700 chlorophyll } \\
\text { a apoprotein* }\end{array}$ \\
\hline Photosynthesis & 16 & $\begin{array}{l}\text { photosystem i p700 chlorophyll } \\
\text { a apoprotein a } 1^{*}\end{array}$ \\
\hline Pyrimidin metabolism & 71 & $\begin{array}{l}\text { deoxyuridine } 5 \text {-triphosphate } \\
\text { nucleotidohydrolase }\end{array}$ \\
\hline Transcription factor & 10 & similar to copia protein \\
\hline mRNA processing & 10 & splicing factor $3 a$ subunit 2 \\
\hline
\end{tabular}

*Indicates annotations from organelle DNA.

glycolysis, tricarboxylic acid [TCA], pentose phosphate and oxidative phosphorylation pathways) in our transcriptomic data. Among all enzymes checked, only hexokinase (for glycolysis) was absent; instead, we found glucokinase, an enzyme capable of performing a similar reaction to the conversion of glucose into glucose-6-phosphate. Further transcripts highly similar to all histone encoding genes (H2A, H2B, H3, H4), histone methyl-transferases and histone deacetylase were present (see Additional file 1). No evidence supporting a weaker expression of these genes was detected (median reads per base: histones 3.1, all other genes 2.9).

Analysis of the translated protein sequences, searched against the PFAM database revealed the most common protein domains in A. spinosum. Among these protein domains, protein kinases and, ion transporters - both common domains for protein-protein interaction and $\mathrm{ABC}$-transporters - were found (Figure 1, see Additional file 2).

We compared the predicted protein data of A. spinosum (expressed sequence tag, EST data) with EST or whole genome data from 18 other dinoflagellate species (see Additional file 3). For comparison within the Rhizaria Alveolate Stramelopile (RAS) group proteins associated with cellular signal transduction, we conducted a database comparison of three diatoms (Fragilariopsis cylindrus [36], Thalassiosira pseudonana [37] and Phaeodactylum tricornutum [38]), the haptophyte Emiliania huxleyi [39], and the cryptomonad Guillardia theta [40]. In addition, the chlorophyte Chlamydomonas reinhardtii [41] served as a representative species of the Plantae. BLAST analysis revealed that $18 \%$ of the proteins found in A. spinosum represent orphan genes (proteins found in a given species that lack homologues in other species), $37 \%$ have homologues 


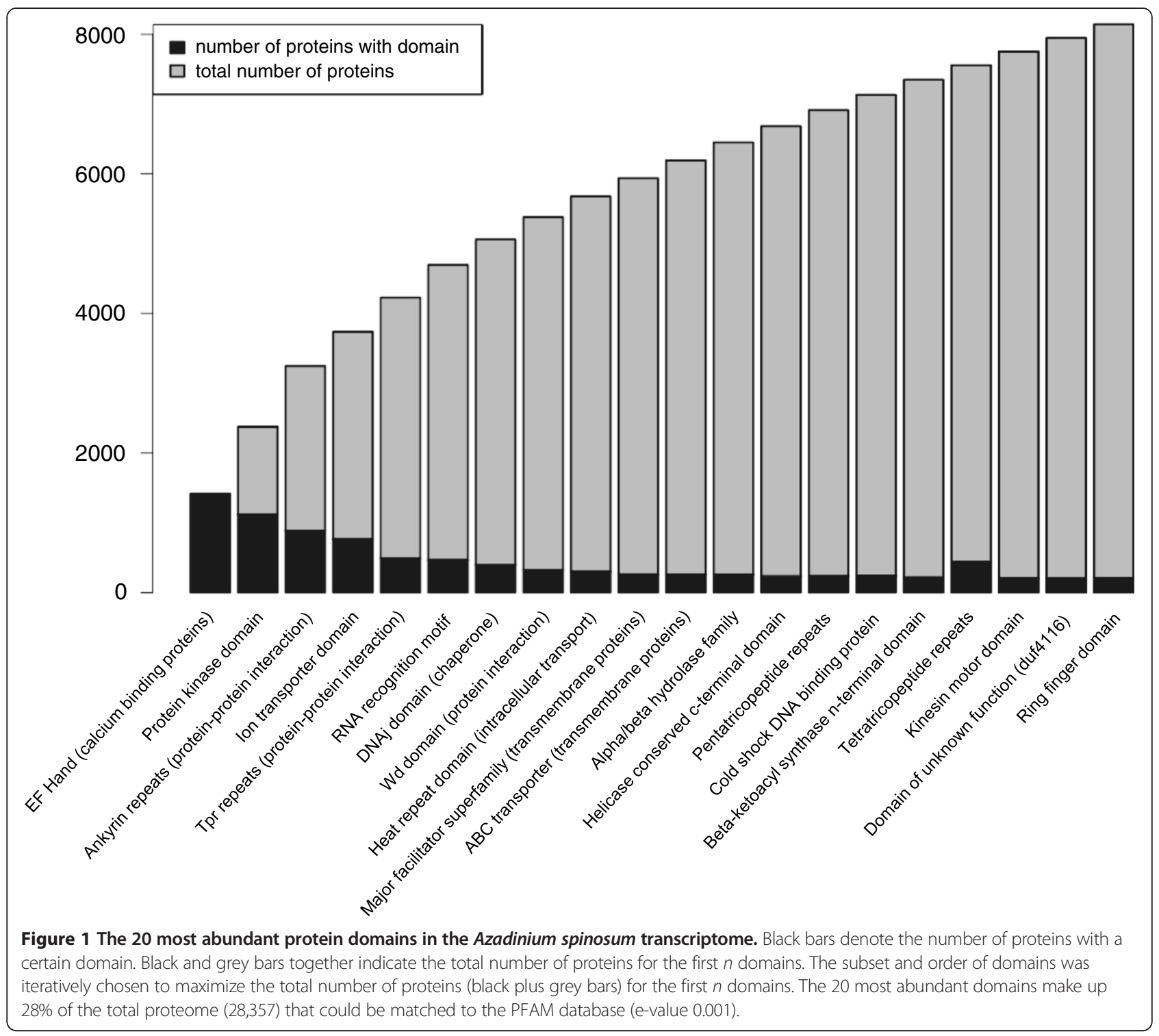

in other dinoflagellate species, $19 \%$ are shared between A. spinosum and the other alveolate groups, and $26 \%$ are shared between $A$. spinosum and $C$. reinhardtii. The relative complement of orphan genes varied widely among the tested dinoflagellate species (Figure 2). For example, A. spinosum, with $18 \%$ orphan genes, together with Amphidinium massartii, Symbiodinium minutum, Karlodinium micrum and Alexandrium ostenfeldii (19\%, 17\%, $17 \%$ and $14 \%$, respectively), grouped among the dinoflagellates having the lowest percentage of orphan genes. In contrast, the dinoflagellates Oxyrrhis marina and Scrippsiella trochoidea were found to have the highest percentages (44\% and $42 \%$, respectively) of orphan genes in the comparisons of this study. The average percentage of orphan genes within the dinoflagellates was $27 \%$.

A. spinosum produces polyketide toxins, and we therefore paid special attention to the enzymes involved in polyketide biosynthesis. We identified a number of proteins putatively involved in this pathway, by both BLAST analysis and by accessing the KEGG-database. Among these proteins, KS, KR, AT, ACP, ACPS, TE and MT were identified, whereas ER proteins were absent from our dataset (Table 3).

Next, we assembled six putative PKS mRNA sequences out of the reads matching PKS sequences (GenBank Accession numbers: KM588916-KM588921; Table 4), of which four were complete and two were partial (splice variants). In five of the six cases, BLASTx analysis revealed high similarity to those of another dinoflagellate, A. ostenfeldii, for which three sequences exist in GenBank (Ac0019, Ac0038 and 10-x_J14). The remaining sequence was found to be most similar to another dinoflagellate sequence, Heterocapsa triquetra; strain HTE5908 (Table 4). 


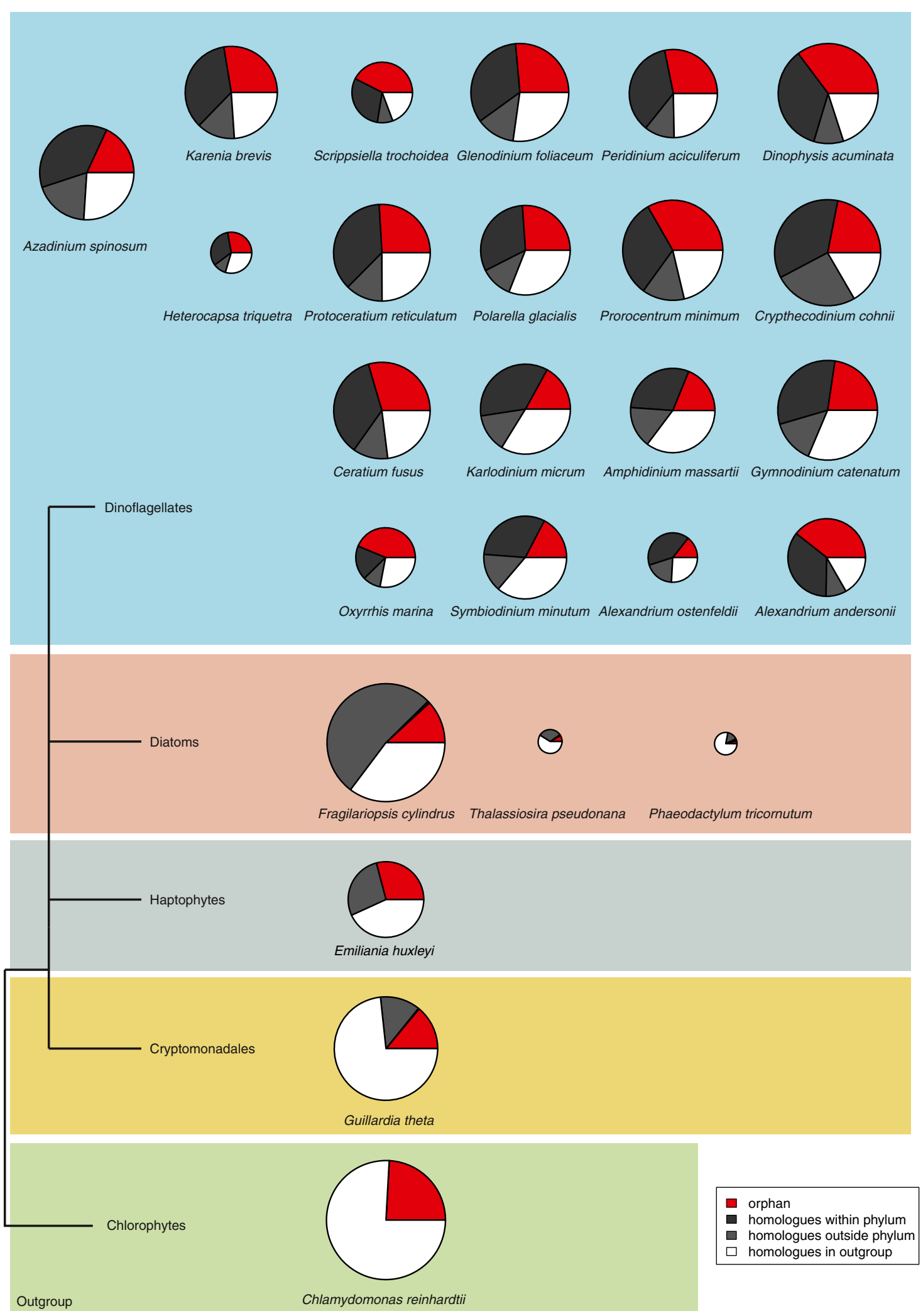

Figure 2 (See legend on next page.) 
(See figure on previous page.)

Figure 2 Transcriptomic data reveals proteins conserved between different dinoflagellates and outgroup species. Comparison between 19 dinoflagellate species including A. spinosum, three diatoms, the haptophyte Emiliania huxleyi, and the cryptomonad Guillardia theta. The size of the pie charts is proportional to the number of sequences analysed. The colour code indicates the hierarchical classification into homology groups defined by descending evolutionary distance, e.g., if a sequence had BLAST hits in the outgroup species Chlamydomonas reinhardtii, it was classified as "homologues in outgroup" irrespective of potential homologues inside the phylum. The schematic phylogeny to the left of the figure represents the relationship between the species analysed. Details about origin and number of sequences analysed can be found in Additional file 3: Table S1.

Each of these six transcripts was also analysed in silico, yielding theoretical protein sizes of approximately 100 KDa after translation for each transcript. Additionally, the presence of a single ketide synthase (KS) domain in each individual transcript was supported by comparing these transcripts against the PFAM database. This analysis indicated the presence of a single ketide synthase (KS) domain in all transcripts, confirming that they are all PKS-related sequences. All transcripts except AS3D905 contained a DTACSS-motif which includes the conserved amino acids (aa) cysteine, histidine and lysine (Figure 3). The presence of these conserved features supports catalytic activity in these transcripts, as they are known to enable protein function [42] in different phylogenetic lineages (e.g., chlorophytes, haptophytes, apicomplexa and dinoflagellates).

In A. spinosum, the mean putative protein length among the six identified PKS transcripts was estimated to be $865 \pm 84$ aa ( \pm s.e.m.). The average protein consisted of an N-terminal region ( $330 \pm 64$ aa), a central KS domain with an estimated size of $388 \pm 29$ aa, and a C-terminal region $(147 \pm 29 \mathrm{aa})$. A conserved motif was found in the $\mathrm{N}$ terminal region of all transcripts (Figure 4), which did not yield any database hits via BLAST and PFAM domain search algorithms. Nevertheless, the motif showed sequence similarity to $K$. brevis, $A$. ostenfeldii and $H$. triqueta sequences in the database. This sequence similarity varied from 28 to $51 \%$ between $K$. brevis and A. spinosum, whereas the maximum sequence similarity between $A$. spinosum and $H$. triqueta (HTE 6310), and between $A$.

Table 3 Assembled Azadinium spinosum transcripts putatively involved in polyketide synthesis, identified by BLAST analysis against the KEGG database

\begin{tabular}{ll}
\hline KEGG database hit (p-value $\mathbf{0 . 0 0 1 )}$ & Frequency in reads \\
\hline Polyketide synthase (PKS) & 22 \\
Ketoacyl synthase (KS) & 157 \\
Ketoreductase (KR) & 25 \\
Acyltransferase (AT) & 41 \\
Acyl carrier protein (ACP) & 27 \\
Acyl carrier protein synthase (ACPS) & 2 \\
Thioesterase (TE) & 19 \\
Enoylreductase (ER) & - \\
Methyltransferase (MT) & 200 \\
\hline
\end{tabular}

spinosum and A. ostenfeldii (Ac0038) sequences was 64\% and $62 \%$, respectively.

\section{A. spinosum PKS transcripts are type I 'Protistan'}

A phylogenetic maximum likelihood approach yielded insights into relationships of PKS sequences from A. spinosum in the current study compared with additional PKS sequences from other dinoflagellates, with an acyl carrier protein synthase (ACPS) sequence as out-group [30]. The resulting overall tree topology was consistent with previously known basic topology for dinoflagellates (Figure 5A). Both ACPS and Type II PKS sequences grouped consistently as out-group taxa with $100 \%$ approximate likelihood ratio (aLRT) and bootstrap support (BT). The transcripts in the current study grouped with strong support alongside Type I PKS sequences, indicating that they are also Type I (Figure 5A).

Support for a 'protistan' clade of PKS Type I sequences, consisting of apicomplexa, dinoflagellates, haptophytes, and chlorophyta was strong/moderate within the phylogeny (98\% aLRT/70\% BT; Figure 5A). Each of these major groups, however, formed a discrete sub-group within the protistan clade. The dinoflagellate clade broke down into two clearly separated sub-clades, one of which included sequences from all dinoflagellate species evaluated in this study (including $A$. spinosum, $A$. ostenfeldii, $H$. triqueta and $K$. brevis). The other dinoflagellate sub-group contained only K. brevis KS sequences (Figure 5B).

$\mathrm{N}$-terminal and C-terminal PKS evolution in A. spinosum The phylogenetic relationship of the PKS N-terminal region among the examined dinoflagellates is shown in a maximum likelihood phylogeny in Figure 4A. The tree reflects the same dinoflagellate resolution found in the KS-based phylogeny (Figure 5B), with one sub-clade comprising only $K$. brevis sequences, and the other consisting of sequences from $A$. spinosum, $A$. ostenfeldii, $H$. triqueta and $K$. brevis. The alignment of the $\mathrm{N}$-terminal region revealed several conserved aa positions, including the highly conserved motive ExExGYLG, which was altered in some of the A. spinosum sequences (Figure 4B). Specifically, in the sequence AS3D901, the whole dinoflagellate-specific $\mathrm{N}$-terminal region was missing. For AS3D903, the GYL part of the motive was replaced by aliphatic aa.

In a final phylogenetic analysis focusing on the PKS Cterminal region, the BLAST algorithm identified 25\% 
Table 4 Sequence properties of the six ketoacyl synthases (KS) transcripts identified in Azadinium spinosum

\begin{tabular}{lllllll}
\hline Sequence ID & Length $(\mathbf{b p})$ & ORF & Amino acids & Best BlastX hit & Similarity (\%) & Accession number \\
\hline AS3D901 & 2909 & $123-2480$ & 785 & Ac0019 & 59 & AFW98411 \\
AS3D902 & 2976 & $61-2901$ & 946 & Ac0019 & 65 & AFW98411 \\
AS3D903 & 2714 & $78-2591$ & 837 & $10-$ x_J14 & 58 & AFW98413 \\
AS3D904 & 3071 & $164-2989$ & 941 & Ac0038 & 71 & AFW98412 \\
AS3D905 & 2902 & $87-2300$ & 737 & Ac0038 & 68 & AFW98412 \\
AS3D906 & 3009 & $42-2888$ & 948 & HTE5908 & 61 & AFW98414 \\
\hline
\end{tabular}

sequence similarity between $A$. spinosum and K. brevis (KB 2006), and 64\% similarity between $A$. spinosum and A. ostenfeldii (Ac0038). The maximum likelihood phylogeny of the C-terminal region generally agreed with the overall (Figure 5A,B) and N-terminal (Figure 4A) phylogenies. We did not find, however, any conserved motif and bootstrap support for most branches was very weak (see Additional file 3: Figure S2).

Mono-functional organization of polyketide synthase in $A$. spinosum

Both our in silico analyses and recent literature reports suggest a mono-functional organization of the KS domain of PKS in Azadinium and other dinoflagellates [30,43], rather than a modular one as in most other phylogenetic groups. Western blot analysis with antibodies targeting the KS domain in protein extracts from $A$. spinosum and two other dinoflagellate species (A. ostenfeldii and $H$. triquetra) confirmed this interpretation. The blotting pattern showed a distinct band at the expected size (approximately $100 \mathrm{kDA}$ ) for a single $\mathrm{KS}$ protein (see Additional file 3: Figure S1).

\section{Discussion}

Features of Azadinium spinosum genome

The current study provides the first genomic characterization of the photosynthetic free-living marine dinoflagellate, A. spinosum [14]. The genomic sequence of $A$. spinosum consists of a high number of repeat structures of low complexity, with protein coding sequences representing only a small fraction $(0.8 \%)$ of the genome. Nevertheless, this fraction of protein coding sequences is higher than the

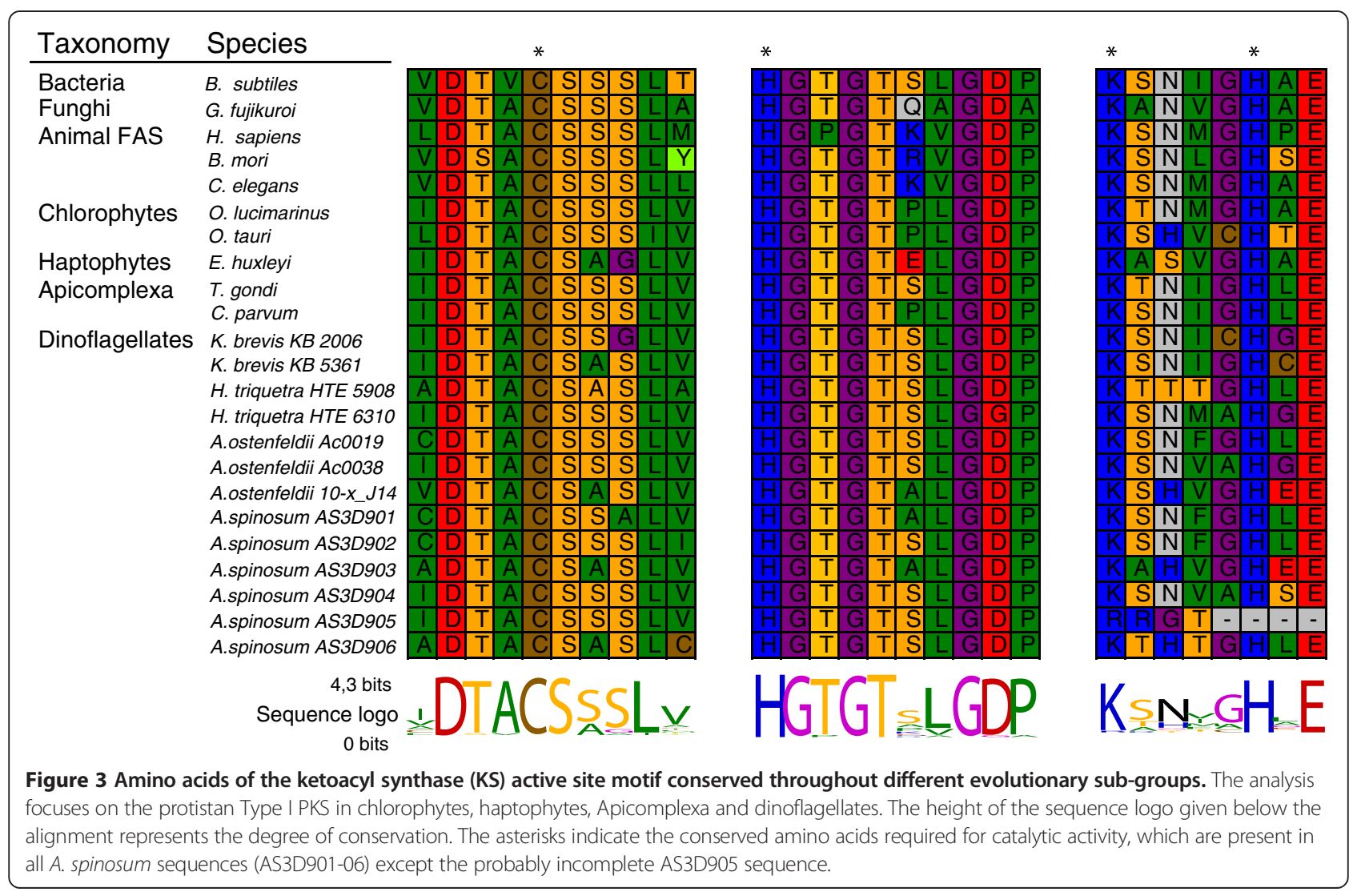




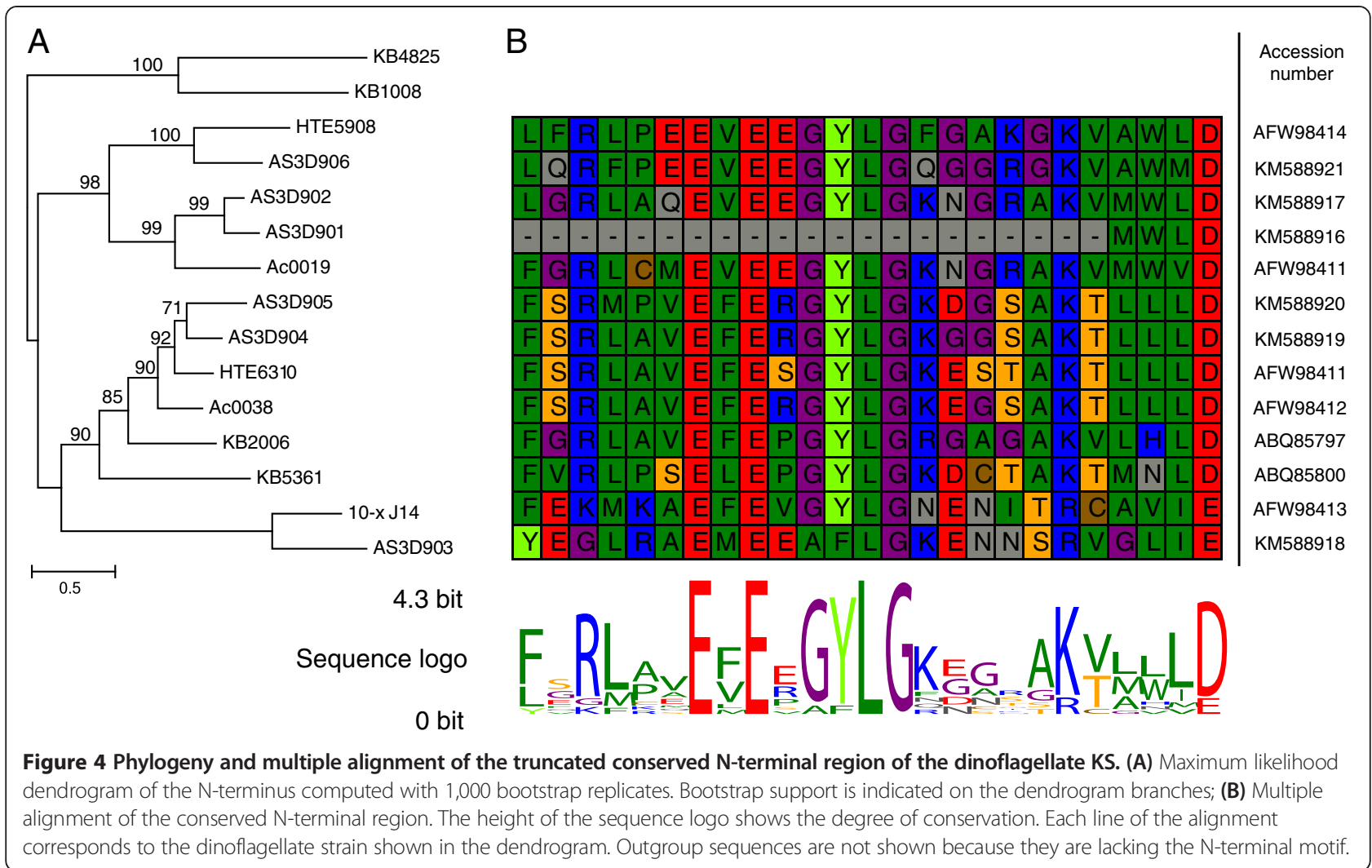

$0.2 \%$ of protein coding regions of the genomes of both $A$. ostenfeldii (genome size: $105.3 \mathrm{~Gb}$ ) and $H$. triquetra (genome size: $18.6-23.6 \mathrm{~Gb})[5,44]$.

The ten most common genes in the genomic data were identified based on read counts, suggesting that genes which are covered by more reads may have more copies in the genome. Dinoflagellates are known for their large gene families with sometimes high gene copy numbers [12]. However, our analysis did not allow us to differentiate whether the reads we identified are derived from multiple copies of the same gene within the genome or from different genes from the same gene family.

A minor fraction $(0.17 \%)$ of the $A$. spinosum sequenced data was assigned to be of retroviral origin. This includes DNA transposons and retrotransposons, which have been found to a similar extent $(0.15 \%)$ in the A. ostenfeldii genome [5]. In the genome of $S$. minutum a slightly higher amount of DNA transposons and retrotransposons $(0.5 \%$ and $1.1 \%$, respectively) were found. Large tandem repeats, which account for at least $58 \%$ of the $A$. ostenfeldii genome [5], were not found in A. spinosum and account for $4.6 \%$ of the comparatively smaller $S$. minutum genome [7]. Tandem repeats may play a role in chromatin packing and genome organization, similar to what is known for telomere regions [45], thus they may play an important role in the organization of the $>50 \mathrm{Gbp}$ genome of $A$. ostenfeldii. Meanwhile, their absence in $A$. spinosum might explain the substantially smaller and less complex genome of this species [32].

\section{Features of the $A$. spinosum transcriptome}

The generated EST data of $A$. spinosum represents a high coverage of the transcriptome. Among all identified transcripts, 844 carried the complete splice leader sequence. Almost all eukaryotic core genes $(94 \%$ in CEGMA analyses) and the essential enzymes from the key metabolic pathways were found. The difference in GC-content we observed between genome and transcriptome is comparable to what was found previously in S. minutum [7].

Unsurprisingly, protein kinase, DNA binding, cytoskeleton proteins, ion channels, and $\mathrm{ABC}$ transporter domains were identified among the most abundant protein domains. These domains play important roles in maintaining essential functions in unicellular organisms, e.g., for signaling pathways, gene expression, cellular organization, and homeostasis of ions and small molecules. These findings are similar to published datasets from other dinoflagellates, however in our analysis the number of domains involved in metabolism seems to be less dominant within the top 20 domains $[4,5]$.

As an interesting exception, hexokinase, the key enzyme of glycolysis, was absent from the A. spinosum transcriptome. The absence of the hexokinase is an indication that enzymatic activity might have been replaced by another 


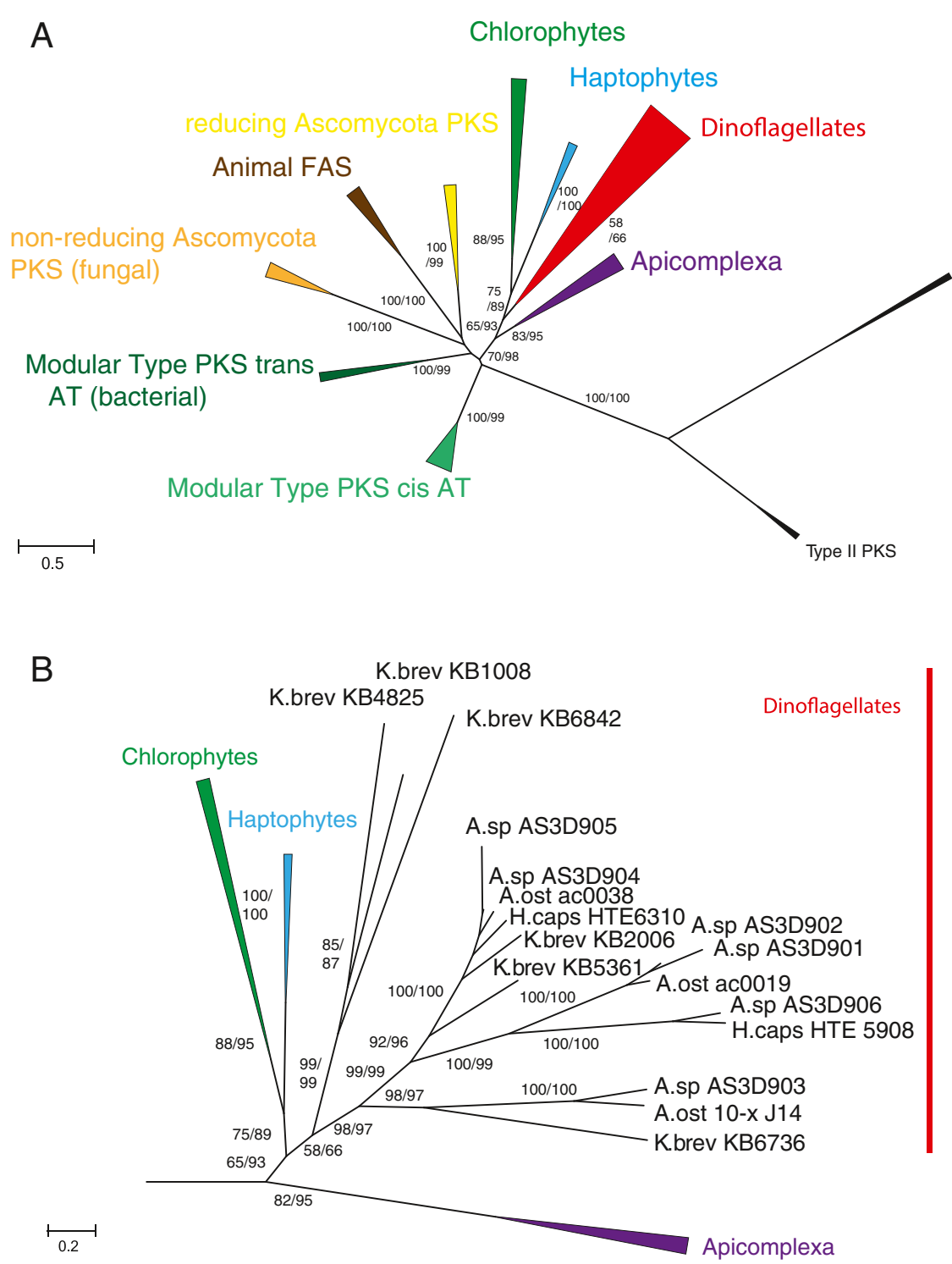

Figure 5 Phylogenetic tree of Type I and Type II KS domains from prokaryotic and eukaryotic PKS and fatty acid synthase (FAS). Type I and Type II KS domains from 60 taxa analysed by maximum likelihood approach. Type II PKS and acyl carrier protein synthases (ACPS) were assigned as outgroups. Approximate likelihood fraction (aLRT) and bootstrap values (BT) $\geq 50 \%$ are displayed on appropriate branches as aLRT/BT. (A) The dinoflagellate KS sequences form a well-supported group within the protistan Type I FAS/PKS clade, consistent with previous topology estimates;

(B) The dinoflagellate KS group splits into two distinct clades; one contains sequences from different species, the other clade consists exclusively of $K$. brevis sequences.

enzyme - in this case, glycokinase - capable of performing similar enzymatic reactions. This is supported by the fact that the reaction catalyzed by both enzymes is essential for energy metabolism. A similar finding was also observed in another study [46]. This could hint towards a general phenomenon in dinoflagellates that should be investigated further, because it suggests a major difference in a basic metabolic pathway.

Additional dinoflagellate genome peculiarities include permanently condensed chromosomes and a low quantity of histones present in the chromatin. Histones have historically been thought to not be expressed or even exist in dinoflagellates [47-49], and the existence of orthologues for all eukaryotic histones has been confirmed only recently $[50,51]$. Here, we found that sequences potentially encoding proteins of all histone core-units and histone-modifying enzymes are present in A. spinosum. We could detect no evidence for a weaker expression of these transcripts in A. spinosum compared to transcripts of all other genes. In contrast to our finding in the transcriptome of the dinoflagellate Lingulodinium histon mRNAs were found in very low abundance [50], suggesting 
differences in abundance of histones between dinoflagellate species.

Approximately $40 \%$ of the predicted proteins of $\mathrm{A}$. spinosum could not be matched to the PFAM database. This is in line with previous findings in dinoflagellates and might be an indication for novel pathways expressed in dinoflagellates [5,52-55]. On average a quarter of the genes found in the dinoflagellate species studied here had no recognizable homologues in other dinoflagellates genera. The estimated number of these 'orphan' genes totaled $27 \%$ of all genes for the dinoflagellates we studied; this is within the range for other well-studied phyla (e.g. bacteria [56], and nematodes [57]), for which 2-50\% of identified genes are orphans.

Different evolutionary mechanisms can lead to the formation of orphan genes. For example, duplication can free gene copies from evolutionary constraints - while the original function is retained in the original gene, the duplicated gene copy can possess new protein functions [58]. An additional source for orphan genes is horizontal gene transfer from other organisms, which has been shown to have the potential to be a significant source of genetic innovation in dinoflagellates [59].

Taken together, a rather unique set of genes may be characteristic for species within the dinoflagellates, potentially reflecting their complex life cycle and nutrition because most are mixo- or heterotrophs and only a few are obligate photoautotrophs [60-62].

\section{Function and evolution of PKS}

All polyketide biosynthetic enzyme functions needed to synthesize the azaspiracid carbon backbone are present in A. spinosum (Table 3). This is to our knowledge the first dinoflagellate dataset where all genes needed for polyketide synthesis were identified. Whether these PKS-related sequences are coding, are involved in fatty acid synthesis or toxin production, and/or have another function remains unclear. However, this set of genes opens new avenues to study toxin synthesis in $A$. spinosum and maybe other dinoflagellates also up to now it remains unknown in which cellular compartment toxin synthesis takes place. PKS enzymes have been shown to be expressed in both chloroplast and cytoplasm, but we could not identify signal peptide sequences which may hint towards a specific cellular compartment. However, co-immunoprecipitation studies have shown that PKS functions in K. brevis are indeed organized in a mono-modular way, meaning that each domain comprises a single enzyme [29,43].

The KS domain is essential to Type I polyketide synthesis, which is carried out in a stepwise manner. Each KS domain elongates the existing carbon chain by condensation of the acetyl-CoA/malonyl-CoA building blocks, with two carbon atoms normally added in each elongation step. This means that Type I modular PKS must contain at least 20 modules to create the common carbon backbone for the diverse set of identified azaspiracid toxins [15]. We analysed six unique PKS transcripts each containing one KS domain, in detail. Whether or not separate transcripts are used or if the same transcripts are recycled during the polyketide synthesis process remains unclear. In any case, the complete AZA structure could be synthesized with the total number of KS, KR, AT and the other domains identified in our dataset.

Analyses of $A$. spinosum full-length PKS transcripts (Figure 3) and of the corresponding Western blots (Additional file 3: Figure S1) confirms the mono-modular functional Type I PKS structure, which might be a common feature in dinoflagellates [29,30]. It has been proposed that this structure likely diverged from multimodular PKS around the time of origin of the dinoflagellates [30,43]. The other protistan groups studied here (haptophytes, chlorophytes and apicomplexa) exhibit the multimodular Type I form. The protist KS groups form well-supported monophyletic clades in the current analysis, consistent with earlier findings [26,30].

The flanking regions of KS proteins identified in $\mathrm{A}$. spinosum contain less conserved motives than in other organisms, but this sequence feature was also found in other dinoflagellates [30]. In the C-terminal region, in particular, no conserved motif was identified in the alignment, supporting the assumption that this is a relict of the linker sequences of the multi-modular PKS Type I. With this linker structure, the single domains could have been separated to allow structural function of the complex enzyme. Adding A. spinosum sequences to the existing C-terminal dataset did not significantly alter the overall topology present in the N-terminal dataset, despite weaker phylogenetic support. In contrast, within the N-terminal sequences, a high degree of conservation was found in the alignment, arguing that the $\mathrm{N}$-terminal has another function rather than acts as a linker region. Instead, the $\mathrm{N}$ terminal region might have an enzymatic or structural function, or could act as a protein-protein binding domain. The conserved $\mathrm{N}$-terminal motif identified previously [30] was found in four of our six A. spinosum sequences. However, we observed an alteration of the GYLG motif towards AFLG. Alterations of the GYLG motif have been reported from the dinoflagellate, Gambierdiscus polynesiensis and also in some $K$. brevis strains where several variants of the GYLG motive were found [63]. The absence or alteration of the conserved Nterminal motif in the remaining two A. spinosum sequences (AS3D901 and AS3D903) could be explained in several ways. For example, these copies might have diverged to play a role in another pathway via gene duplication. Alternatively, these differences may lead to alterations in polyketide synthesis. Finally, these two sequences may simply represent non-functional transcripts 
or pseudogenes. Functional tests are required to elucidate the role of the PKS genes as well as of the C- and Nterminal sequences.

\section{Conclusions}

We characterized the transcriptome of the toxic dinoflagellate A. spinosum, revealing that it possesses a low number of orphan genes compared to other tested dinoflagellate species. With respect to toxin synthesis, we detected transcripts of all genes essential for polyketide synthesis in A. spinosum. As the number of transcriptomic datasets for different dinoflagellate species increases, deeper insights into the functional differences between toxic and non-toxic variants, even within a species, as well as into mechanisms of $\mathrm{HAB}$ formation, will be gained.

\section{Methods}

Maintenance and harvesting of dinoflagellate cultures Azadinium spinosum cultures of strain 3D9 isolated from the Scottish east coast $\left(57^{\circ} 3.9^{\prime} \mathrm{N} ; 02^{\circ} 30.2^{\prime} \mathrm{W}\right)$ were grown as described in Tillmann et al. [14]. In brief, cultures were grown at $20^{\circ} \mathrm{C}$ at a salinity of $32 \mathrm{PSU}$. All exponentially growing cultures were then harvested by centrifugation for $15 \mathrm{~min}$ at $3200 \times \mathrm{g}$ with fixed angle rotor (Eppendorf 5810 R, Eppendorf, Hamburg, Germany).

\section{Methods for DNA; extraction}

Following centrifugation, cell pellets were re-suspended in Tissue and Cell Lysis Buffer (DNeasy Plant kit; Qiagen, Hamburg, Germany) and transferred into a $2 \mathrm{ml}$ cryovial containing acid-washed glass beads (Sigma-Aldrich, Steinheim, Germany). Cell lysis was achieved with a Bio101 FastPrep instrument (Thermo, Savant Illkirch, France) run at maximum speed $\left(6.5 \mathrm{~ms}^{-1}\right)$ for $45 \mathrm{~s}$. DNA extraction proceeded according to the DNeasy Plant kit protocol.

\section{Shotgun sequencing}

Prior to sequencing, DNA was sheared and contaminants and small fragments were removed with the Ampure Bead PCR purification system (Invitrogen, Karlsruhe, Germany) following the standard protocol for 454-library preparation and shotgun sequencing (Roche, Mannheim Germany). Sequencing was then carried out on a Roche GS Junior machine (Roche, Mannheim, Germany) following standard protocols.

\section{Sequencing post-run processing}

The associated 454-sequencing software (Roche GS Junior Version 2.8) was used for quality control and contig assembly. All sequencing reads featuring inaccurate key sequences, chimeric sequences, biased nucleotides, or unidentified nucleotides were regarded as low quality reads and were discarded. A total of 103,860 high quality reads, yielding 37,739,423 bp of genomic information, were retained for analysis.

\section{Sequence analysis of genomic DNA reads}

Low overall genomic coverage and a very large genome size meant that assembly of the retained reads was unrealistic. Reads were thus analysed with the program RepeatMasker ver. 4.0.5 [34] to establish the repeat structure of the genome. To determine the potential proportion of protein-coding sequence, annotation of the high quality reads was also performed. The Blast2go algorithm (www.blast2go.org) was applied against the Swissprot database, and only reads with an e-value below $10^{-7}$ were considered in the analysis.

\section{Genome size estimation}

The genome size of $A$. spinosum was estimated by DNA extraction and subsequent qPCR. The DNA content was calculated using a standard curve. For more details see [32].

\section{RNA methods; extraction}

Cell pellets obtained after centrifugation of exponentially growing cultures were immediately re-suspended in $1 \mathrm{ml}$ of $60^{\circ} \mathrm{C}$ hot TriReagent (Sigma-Aldrich, Steinheim, Germany) and transferred into a $2 \mathrm{ml}$ cryovials containing acid washed glass beads (Sigma-Aldrich, Steinheim, Germany). As for DNA extraction, cell lysis was achieved with a Bio101 FastPrep instrument (Thermo Savant Illkirch, France) run at maximum speed $\left(6.5 \mathrm{~ms}^{-1}\right)$ for 45 s. RNA isolation was then performed as described in [64]. In brief, after thawing the cell lysate on ice, $200 \mu \mathrm{l}$ of pure chloroform was added to each sample. The sample was vortexed thoroughly and incubated for $10 \mathrm{~min}$ at room temperature. The aqueous phase was separated by centrifugation and transferred into a new vial together with $100 \%$ isopropanol and incubated at $-20^{\circ} \mathrm{C}$ to precipitate the RNA. The pellet was collected by centrifugation at $4^{\circ} \mathrm{C}$, washed with $70 \%$ ethanol, air-dried and re-suspended in RNase-free water (Qiagen, Hilden, Germany).

Only RNA samples with high quality (OD 260/280 > 2 and OD260/230 > 1.8), determined with a NanoDrop ND100 spectrometer (PeqLab, Erlangen, Germany), and high RNA integrity, checked with the Agilent RNA Nano Chip Assay (Agilent, Santa Clara, USA), were used for transcriptome sequencing.

\section{RNA sequencing}

RNA sequencing and post-run processing was performed by The Marine Microbial Eukaryotic Transcriptome Sequencing Project (MMETSP). 


\section{Analysis of transcriptome data}

An assembly pipeline from the MMETSP was to assemble high quality raw reads into contigs, which were translated into amino acid sequences and blasted against the PFAM database (PFAM count (e-value $<0.001)$ file Supplement).

\section{Homology analysis}

We used the NCBI blast suite (version 2.2.28+) to compare the set of 69,956 predicted protein fragments with gene predictions and EST data from the following species: dinoflagellates: Alexandrium andersonii, Alexandrium ostenfeldii, Amphidinium massartii, Ceratium fusus, Crypthecodinium cohnii, Dinophysis acuminate, Glenodinium foliaceum, Gymnodinium catenatum, Heterocapsa triquetra, Karenia brevis, Karlodinium micrum, Oxyrrhis marina, Peridinium aciculiferum, Polarella glacialis, Prorocentrum minimum, Protoceratium reticulatem, Scrippsiella trochoidea, Symbiodinium minutum; diatoms: Fragilariopsis cylindrus, Phaeodactylum tricornutum, Thalassiosira pseudonana; haptophyte: Emiliania huxleyi; cryptomonad: Guillardia theta; and the chlorophyte Chlamydomonas reinhardtii. We computed all pairwise BLAST comparisons (BLASTp, tBLASTx, BLASTx, and tBLASTn, depending on the type of database) at a threshold of e-value $<0.001$ and counted the number of sequences with hits in the other species. For the comparison to the CEGMA data set [35], we used the hmmer package (version 3.0) to detect hits (e-value $<0.001)$ to any of the CEGMA profile HMMs.

\section{Phylogenetic analyses}

Additional amino acid sequences were obtained from the NCBI GenBank and from [30]. A representative dataset of 65 Type I and Type II PKS sequences covering the major clades of prokaryota, fungi, animals, apicomplexa, haptophytes and chlorophytes was used for maximum likelihood phylogenetic analyses. A multi-sequence alignment was created in MEGA 5.2 [65] with the implemented MUSCLE algorithm [66]. A maximum likelihood tree was computed in PhyML 3.0 [67] under assumption of the La-Gascuel amino acid replacement matrix [68]; likelihood ratio tests [69] and 1,000 bootstrap analyses were performed as a measure of the validity of each branch.

\section{Analyses of the $\mathrm{N}$ - and C-terminal region}

The $\mathrm{N}$ - and $\mathrm{C}$ - terminal regions of the dinoflagellate KS sequences were truncated from the KS domain and blasted with tBLASTx against the NCBI and PFAM databases. No significant hits other than to known KS sequences in the database were obtained by BLASTx analysis. Multiple alignment and subsequent phylogenetic trees were calculated as described for the KS domain.

\section{Western immunoblotting of dinoflagellate PKS}

Western blot analysis of protein extracts from A. ostenfeldii AOSH 2 and $\mathrm{NCH}$ 85, A. tamarense Atam5, H. triquetra SCCAP strain K-0481, E. huxleyi, Phaeodactylum sp., A. spinosum and S. trochoidea was performed according to [30]. In brief, $10 \mathrm{mg}$ of total protein extract was separated on a $10 \%$ SDS/polyacrylamide gel and transferred onto polyvinylidene fluoride membranes by Western Blot. Membranes were blocked with 5\% skimmed milk in Trisbuffered saline with $0.5 \%$ Tween 20 (TBS-T) for $1 \mathrm{~h}$. Primary antibodies (Rabbit anti-K. brevis KS KB 2006 1:5000) were diluted in 5\% skimmed milk in TBS-T and the membranes were incubated at $4^{\circ} \mathrm{C}$ overnight. Subsequently, the membranes were washed three times with TBS-T and incubated with the appropriate secondary antibody dilution (Goat anti-rabbit 1:20000 Peroxidase-conjugated) (Sigma-Aldrich, Schnelldorf, Germany) in 5\% skimmed milk/TBS-T for $2 \mathrm{~h}$ at room temperature.

\section{Additional files}

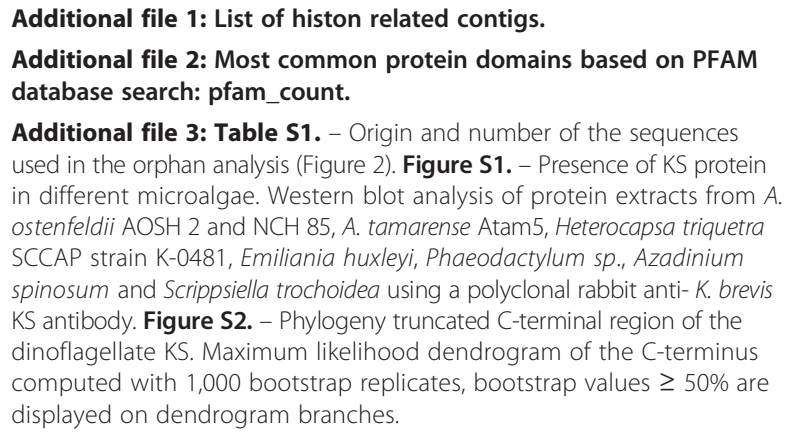

Additional file 3: Table S1. - Origin and number of the sequences used in the orphan analysis (Figure 2). Figure S1. - Presence of KS protein in different microalgae. Western blot analysis of protein extracts from $A$. ostenfeldii AOSH 2 and NCH 85, A. tamarense Atam5, Heterocapsa triquetra SCCAP strain K-0481, Emiliania huxleyi, Phaeodactylum sp., Azadinium spinosum and Scrippsiella trochoidea using a polyclonal rabbit anti- K. brevis KS antibody. Figure S2. - Phylogeny truncated C-terminal region of the dinoflagellate KS. Maximum likelihood dendrogram of the C-terminus computed with 1,000 bootstrap replicates, bootstrap values $\geq 50 \%$ are displayed on dendrogram branches.

\section{Competing interests}

The authors declare that they have no competing interests.

\section{Authors' contributions}

JMM and UJ designed the study. JMM and KE performed the experiments. JMM, CR and UJ performed the bioinformatics and analysed the data. All authors read, edited and approved the final manuscript.

\section{Acknowledgements}

The authors are grateful to Dr. Frances Van Dolah (NOAA Center for Coastal and Environmental Health and Biomolecular Research, Charleston, South Carolina, USA) for the custom peptide polyclonal antibodies specific for Karenia brevis KS domain (KB2006; GenBank accession no. EF410007). This research was conducted within the PACES research program of the Alfred-Wegener-Institute Helmholtz-Zentrum für Polar- und Meeresforschung as part of the Coastal theme (WP2).

\section{Funding}

Financial support was provided by the PACES research program of the Alfred-Wegener-Institute Helmholtz-Zentrum für Polar- und Meeresforschung. The Gordon and Betty Moore Foundation funded sequencing, assembly, and preliminary annotation through Grant GBMF2637 to the National Center for Genome Resources.

\section{Author details}

${ }^{1}$ Ecological Chemistry, Alfred Wegener Institute for Polar and Marine Research, Bremerhaven, Germany. ${ }^{2}$ Evolutionary biology, Max Planck Institute for Developmental Biology, Tübingen, Germany. ${ }^{3}$ Adenoviridae: Receptors, 
Trafficking and Vectorology, Institut de Génétique Moléculaire de Montpellier, Montpellier, France.

Received: 11 June 2014 Accepted: 24 December 2014 Published online: 23 January 2015

\section{References}

1. Hallegraeff GM. A review of harmful algal blooms and their apparent global increase. Phycologia. 1993;32:79-99.

2. Harper JT, Waanders E, Keeling PJ. On the monophyly of chromalveolates using a six-protein phylogeny of eukaryotes. Int J Syst Evol Micr. 2005;55:487-96.

3. Moreno-Diaz-de-la-Espina S, Alverca E, Cuadrado A, Franca S. Organization of the genome and gene expression in a nuclear environment lacking histons and nucleosomes: the amazing dinoflagellates. Eur J Cell Biol. 2005;84:137-49.

4. Lowe CD, Mello LV, Samatar N, Martin LE, Montagnes DJS. The transcriptome of the novel dinoflagellate Oxyrrhis marina (Alveolata: Dinophyceae): response to salinity examined by 454 sequencing. BMC genomics. 2011;12:519.

5. Jaeckisch N, Yang I, Wohlrab S, Gloeckner G, Kroymann J, Vogel H, et al. Comparative genomic and transcriptomic characterization of the toxigenic marine dinoflagellate Alexandrium ostenfeldii. PLOS ONE. 2011;6:e28012. doi:10.1371/journal.pone.0028012.

6. Jackson CJ, Gornik SG, Waller RF. The mitochondrial genome and transcriptome of the basal dinoflagellate Hematodinium sp:: character evolution within the highly derived mitochondrial genomes of dinoflagellates. Genome Biol Evol. 2012:4:59-72.

7. Shoguchi E, Shinzato C, Kawashima T, Gyoja F, Mungpakdee S, Koyanagi R, et al. Draft assembly of the Symbiodinium minutum nuclear genome reveals dinoflagellate gene structure. Curr Biol. 2013;23:1399-408.

8. Dodge JD. The dinophyceae. The chromosome of the algae. Edited by Godward MBE. London: Arnold; 1966.

9. Rizzo PJ. Those amazing dinoflagellate chromosomes. Cell Res. 2003;13:215-7.

10. Rill RL, Livolant F, Aldrich HC, Davidson MW. Electron microscopy of liquid crystalline DNA: Direct evidence for cholesteric-like organization of DNA in dinoflagellate chromosomes. Chromosoma. 1989;98:280-6.

11. Lin S. Genomic understanding of dinoflagellates. Res Microbiol. 2011;166:551-69.

12. Hou Y, Lin S. Distinct gene number-genome size relationships for eukaryotes and non-eukaryotes: gene content estimation for dinoflagellate genomes. PLOS ONE. 2009;4:e6978. doi:10.1371/journal.pone.0006978.

13. Beauchemin M, Roy S, Daoust P, Dagenais-Bellefeuille S, Bertomeu T, Letourneau $L$, et al. Dinoflagellate tandem array gene transcripts are highly conserved and not polycistronic. PNAS. 2012;109:15793-8.

14. Tillmann U, Elbrächter M, Krock B, John U, Cembella A. Azadinium spinosum gen. et sp. nov. (Dinophyceae) identified as a primary producer of azaspiracid toxins. Eur J Phycol. 2009:44:63-79.

15. Krock B, Tillmann U, John U, Cembella AD. Characterization of azaspiracids in plankton size-fractions and isolation of an azaspiracid-producing dinoflagellate from the North Sea. Harmful Algae. 2008; doi:10.1016/j.hal.200806.003.

16. James KJ, Furey A, Lehane M, Ramstad H, Aune T, Hovgaard P, et al. First evidence of an extensive Northern European distribution of Azaspiracid Poisoning (AZP) toxins in shellfish. Toxicon. 2002;40:909-15.

17. Magdalena AB, Lehane M, Krys S, Fernandez ML, Furey A, James KJ. The first identification of azaspiracids in shellfish from France and Spain. Toxicon. 2003:42:105-8

18. Taleb H, Vale P, Amanhir R, Benhadouch A, Sagou R, Chafik A. First detection of azaspiracids in mussels. North West Afr J Shellfish Res. 2006;25:1067-70.

19. Twiner MJ, Rehmann N, Hess P, Doucette GJ. Azaspirazid shellfish poisoning: a review on the chemistry, ecology, and toxicology with emphasis on human health impacts. Marine Drugs. 2008;6:39-72.

20. Furey A, O'Doherty S, O'Callaghan K, Lehane M, James KJ. Azaspiracid poisoning (AZP) toxins in shellfish: toxicological and health considerations. Toxicon. 2010;56:173-90.

21. Tillmann U, Salas R, Jauffrais T, Hess P, Silke J. Azaspiracids. The producing organism(s): biology and trophic transfer. In: Botana L, editor. Seafood and freswater toxins. Pharmacology, physiology, and detection, seafood and freshwater toxins. Pharmacology, physiology, and detection. Boca Raton: CRC Press Boca Raton; 2014. p. 1197.

22. Staunton J, Weissman KJ. Polyketide biosynthesis: a millennium review. Nature Prod Rep. 2001;18:380-416.

23. Gokhale RS, Dipika T. Biochemistry of polyketide synthases. In: Rehm HJ, Reed G, editors. Biotechnology. 2nd ed. Weinheim, Germany: Wiley-VCH Verlag GmbH; 2001. p. 341-72.
24. Shen B. Polyketide biosynthesis beyond the type I, II and III polyketide synthase paradigms. Curr Opin Chem Biol. 2003;7:285-95.

25. Zhu G, LaGier MJ, Stejskal F, Millership JJ, Cai X, Keithly JS. Cryptosporidium parvum: the first protist known to encode a putative polyketide synthase. Gene. 2002;298:79-89.

26. John U, Beszteri B, Derelle E, Van de Peer Y, Read B, Moreau H, et al. Novel insights into evolution of protistan polyketide synthases through phylogenomic analysis. Protist. 2008;159:21-30

27. John U, Beszteri S, Gloeckner G, Singh R, Medlin L, Cembella AD. Genomic characterisation of the ichthyotoxic prymnesiophyte Chrysochromulina polylepis, and the expression of polyketide synthases genes in synchronised cultures. Eur J Phycol. 2010;45:215-29.

28. Freitag M, Beszteri S, Vogel $H$, John U. Effects of physiological shock treatments on toxicity and polyketide synthase gene expression in Prymnesium parvum (Prymnesiophyceae). Eur J Phycol. 2011;46:193-201. doi:10.1080/09670262.2011.591438.

29. Monroe E, Van Dolah FM. The toxic dinoflagellate Karenia brevis encodes novel type I-like polyketide synthases containing discrete catalytic domains. Protist. 2008;159:471-82.

30. Eichholz K, Beszteri B, John U. Putative monofunctional type I polyketide synthase units: a dinoflagellate-specific feature? PLoS ONE. 2012;7:e48624. doi:10.1371/journal.pone.0048624.

31. Keeling PJ, Burger G, Durnford DG, Lang BF, Lee RW, Pearlman RE, et al. The tree of eukaryotes. Trends Ecol Evol. 2005;20:670-6.

32. Toebe K, Joshi A, Messtorff P, Tillmann U, Cembella A, John U. Molecular discrimination of taxa within the dinoflagellate genus Azadinium, the source of azaspiracid toxins. J Plankton Res. 2013;35:225-30.

33. Keeling PJ, Burki F, Wilcox HM, Allam B, Allen EE, Amaral-Zettler LA, et al. The Marine Microbial Eukaryote Transcriptome Sequencing Project (MMETSP): illuminating the functional diversity of eukaryotic life in the oceans through transcriptome sequencing. PloS Biol. 2014;12:e001889.

34. Smit AFA, Hubley R, Green P. RepeatMasker Open-3.0. http://www.repeatmasker.org.1996-2010.

35. Parra G, Bradnam K, Korf I. CEGMA: a pipline to accurately annotate core genes in eukaryotic genomes. Bioinformatics. 2007;23:1061-7.

36. Lommer M, Specht M, Roy AS, Kraemer L, Andreson R, Gutowska MA, et al. Genome and low-iron response of an oceanic diatom adapted to chronic iron limitation. Genome Bio. 2012;13:R66. doi:10.1186/gb-2012-13-7-r66.

37. Armbrust EV, Berges JA, Bowler C, Green BR, Martinez D, Putnam NH, et al. The genome of the diatom Thalassiosira pseudonana: ecology, evolution, and metabolism. Science. 2004;306:79-86.

38. Bowler C, Allen AE, Badger JH, Grimwood J, Jabbari K, Kuo A, et al. The Phaeodactylum tricornutum genome reveals the evolutionary history of diatom genomes. Nature. 2008;456:239-44.

39. Read BA, Kegel J, Klute MJ, Kuo A, Lefebvre SC, Maumus F, et al. Pan genome of the phytoplankton Emiliania underpins its global distribution. Nature. 2013;499:209-13.

40. Curtis BA, Tanifuji G, Burki F, Gruber A, Irimia M, Maruyama S, et al. Algal genomes reveal evolutionary mosaicism and the fate of nucleomorphs. Nature. 2012;492:59-65.

41. Merchant SS, Prochnik SE, Vallon O, Harris EH, Karpowicz SJ, Witman GB, et al. The Chlamydomonas genome reveals the evolution of key animal and plant functions. Science. 2007;318:245-50.

42. von Wettstein-Knowles P, Olsen JG, McGuire K, Henriksen A. Fatty acid synthesis -role of active site histidines and lysine in Cys-His-His-type beta-ketoacyl-acyl carrier protein synthases. FEBS J. 2006;273:695-710.

43. Van Dolah FM, Zippay ML, Pezzolesi L, Rein KS, Johanson JG, Morey JS, et al. Subcellular localization of dinoflagellate polyketide synthases and fatty Acid synthase activity. J Phycol. 2013;49:118-1127.

44. McEwan M, Raheel H, Claudio HS, Patrick JK. Nuclear genome sequence survey of the dinoflagellate Heterocapsa triquetra. J Eukaryot Microbiol. 2008;55:530-5.

45. Nikitina T, Woodcock CL. Closed chromatin loops at the ends of chromosomes. J Cell Biol. 2004;166:161-5.

46. Butterfield ER, Howe CJ, Ellen R, Nisbet R. An analysis of dinoflagellate metabolism using EST data. Protist. 2013;164:218-36.

47. Hackett JD, Anderson DM, Erdner DL, Bhattacharya D. Dinoflagellates: a remarkable evolutionary experiment. Am J Bot. 2004;91:1523-34.

48. Zhang H, Hou Y, Miranda L, Campbell DA, Sturm NR, Gaasterland T, et al. Spliced leader RNA trans-splicing in dinoflagellates. PNAS. 2007;104:4618-23. 
49. Lin S, Zhanga H, Zhuanga Y, Tranb B, Gillb J. Spliced leader-based metatranscriptomic analyses lead to recognition of hidden genomic features in dinoflagellates. PNAS. 2010;107:20033-8.

50. Roy S, Morse D. A full suite of histones modifying genes are transcribed in the dinoflagellate Lingulodinium. PloS One. 2012;7:e34340. doi:10.1371/ journal.pone.0034340.

51. Gornik SG, Ford KL, Mulhern TD, Bacic A, McFadden Gl, Waller RF. Loss ofnucleosomal DNA condensation coincides with appearance of a novelnuclear protein in dinoflagellates. Curr Biol. 2012;22:2303-12.

52. John U, Groben R, Beszteri B, Medlin L. Utility of amplified fragment length polymorphisms (AFLP) to analyse genetic structure within the Alexandrium tamarense species complex. Protist. 2004;155:169-79.

53. Van Dolah FM, Lidie KB, Monroe EA, Bhattacharya D, Campbell L, Doucette GJ, et al. The Florida red tide dinoflagellate Karenia brevis: New insights into cellular and molecular processes underlying bloom dynamics. Harmful Algae. 2007;8:562-72.

54. Uribe P, Fuentes D, Valdés J, Shmaryahu A, Zuniga A, Holmes D, et al. Preparation and analysis of an expressed sequence tag library from the toxic dinoflagellate Alexandrium catenella. Mar Biotechnol. 2008;10:692-700.

55. Yang I, John U, Beszerti S, Gloeckner G, Krock B, Goesmann A, et al. Comparative gene expression in toxic vs non-toxic strains of the marine dinoflagellate Alexandrium minutum. BMC genomics. 2010;11:248.

56. Fukuchi S, Nishikawa K. Estimation of the number of authentic orphan genes in bacterial genomes. DNA Res. 2004;11:219-31.

57. Roedelsperger C, Streit A, Sommer RJ. Structure, function and evolution of the nematode genome. In: eLS. Chichester: John Wiley \& Sons, Ltd; 2013. doi:10.1002/9780470015902.a0024603.

58. Katju V, Lynch M. On the formation of novel genes by duplication in the Caenorhabditis elegans gemone. Mol Biol Evol. 2006;23:1056-67.

59. Wisecaver JH, Brosnahan ML, Hackett JD. Horizontal gene transfer is a significant driver of gene innovation in dinoflagellates. Genome Biol Evol. 2013:5:2368-81.

60. Jeong HJ, Yoo YD, Park JY, Song JY, Kim ST, Lee SH, et al. Feeding by phototrophic red-tide dinoflagellates: five species newly revealed and six species previously known to be mixotrophic. Aquat Microb Ecol. 2005:40:133-50.

61. Jeong HJ, Yoo YD, Kim JS, Seong KA, Kang NS, Kim TH. Growth, feeding and ecological roles of the mixotrophic and heterotrophic dinoflagellates in marine planktonic food webs. Ocean Sci J. 2010;45:65-91.

62. Stoecker DK. Mixotrophy among dinoflagellates. J Eukaryot Microbiol. 1999;46:397-401.

63. Pawlowiez R, Morey JS, Darius HT, Chinain M, Van Dolah FM. Transcriptome sequencing reveals single domain type I-like polyketide synthases in the toxic dinoflagellate Gambierdiscus polynesiensis. Harmful Algae. 2014;36:29-37.

64. Wohlrab S, Iversen M, John U. A molecular and co-evolutionary context for grazer induced toxin production in Alexandrium tamarense. PLOS ONE. 2010:5:e15039. doi:10.1371/journal.pone.0015039.

65. Tamura K, Peterson D, Peterson N, Stecher G, Nei M, Kumar S. MEGA5: molecular evolutionary genetics analysis using maximum likelihood, evolutionary distance, and maximum parsimony methods. Mol Biol Evol. 2011;28:2731-9.

66. Edgar RC. MUSCLE: multiple sequence alignment with high accuracy and high throughput. Nucleic acids res. 2004;32:1792-7.

67. Guindon S, Dufayard JF, Lefort V, Anisimova M, Hordijk W, Gascuel O. New algorithms and methods to estimate maximum-likelihood phylogenies: assessing the performance of PhyML 3.0. Syst Biol. 2010;59:307-21.

68. Le SQ, Gascuel O. An improved general amino acid replacement matrix. Mo Biol Evol. 2008;25:1307-20.

69. Anisimova M, Gascuel O. Approximate likelihood-ratio test for branches: a fast, accurate, and powerful alternative. Syst Biol. 2006;55:539-52.

\section{Submit your next manuscript to BioMed Central and take full advantage of:}

- Convenient online submission

- Thorough peer review

- No space constraints or color figure charges

- Immediate publication on acceptance

- Inclusion in PubMed, CAS, Scopus and Google Scholar

- Research which is freely available for redistribution

Submit your manuscript at www.biomedcentral.com/submit 